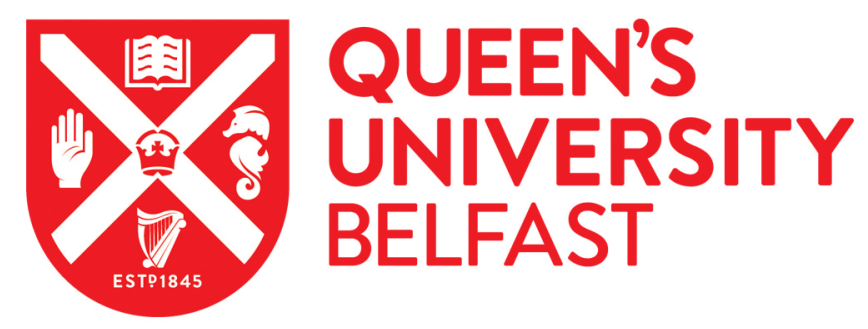

\title{
Random Regret Minimization: Exploration of a New Choice Model for Environmental and Resource Economics
}

Thiene, M., Boeri, M., \& Chorus, C. G. (2012). Random Regret Minimization: Exploration of a New Choice Model for Environmental and Resource Economics. Environmental \& resource economics, 51(3), 413-429.

https://doi.org/10.1007/s10640-011-9505-7

Published in:

Environmental \& resource economics

Document Version:

Peer reviewed version

Queen's University Belfast - Research Portal:

Link to publication record in Queen's University Belfast Research Portal

Publisher rights

(c) Springer Science+Business Media B.V. 2011. This work is made available online in accordance with the publisher's policies. Please refer to any applicable terms of use of the publisher.

\section{General rights}

Copyright for the publications made accessible via the Queen's University Belfast Research Portal is retained by the author(s) and / or other copyright owners and it is a condition of accessing these publications that users recognise and abide by the legal requirements associated with these rights.

Take down policy

The Research Portal is Queen's institutional repository that provides access to Queen's research output. Every effort has been made to ensure that content in the Research Portal does not infringe any person's rights, or applicable UK laws. If you discover content in the Research Portal that you believe breaches copyright or violates any law, please contact openaccess@qub.ac.uk. 


\title{
Random Regret Minimization: Exploration of a new choice model for environmental and resource economics
}

\begin{abstract}
This paper introduces the discrete choice model-paradigm of Random Regret Minimization (RRM) to the field of environmental and resource economics. The RRMapproach has been very recently developed in the context of travel demand modelling and presents a tractable, regret-based alternative to the dominant choice-modelling paradigm based on Random Utility Maximization-theory (RUM-theory). We highlight how RRM-based models provide closed form, logit-type formulations for choice probabilities that allow for capturing semi-compensatory behaviour and choice setcomposition effects while being equally parsimonious as their utilitarian counterparts. Using data from a Stated Choice-experiment aimed at identifying valuations of characteristics of nature parks, we compare RRM-based models and RUM-based models in terms of parameter estimates, goodness of fit, elasticities and consequential policy implications.
\end{abstract}

Keywords: Random Regret Minimization; Random Utility Maximization; Discrete choice modelling, Outdoor recreation, Environmental policy. 


\section{Introduction}

Recent years have witnessed an increasing focus on the treatment of behavioural issues in discrete choice-modelling in the field of environmental and resource economics (e.g. Campbell et al., 2008; Scarpa et al., 2008; Thiene and Scarpa, 2009; Beharry-Borg et al., 2009; Hensher et al., 2011; Morey and Thiene, submitted). Researchers in this field have been using discrete choice modelling of revealed and stated preference data to estimate the value of (or willingness to pay for) attributes of environmental goods and services or to predict welfare changes due to the implementation of specific policy options providing different mixes of such goods and services. This literature includes, among others, applications on land use preferences (Campbell et al., 2008; Johnston and Duke, 2007; Meyerhoff et al., 2010), on recreation demand (Hanley et al., 2002; Bullock et al., 1998; Scarpa and Thiene, 2005; Herriges and Phaneuf, 2002; Morey et al., 2006; Thiene and Scarpa, 2008) and on preferences for developing tourism (Hearne and Salinas, 2002; DeShazo et al., 2009).

Practically without exception, these models are based on (linear-additive) Random Utility Maximization (RUM - McFadden, 1974, Ben-Akiva \& Lerman, 1985; Train, 2009). As is widely acknowledged, RUM's popularity is mainly due to its strong econometric foundations, its conceptual elegance and its formal tractability: many of its models have closed-form formulations for choice probabilities, and most can be easily coded and estimated using standard discrete choice-software packages.

Notwithstanding RUM's popularity among choice-modellers, various attempts have been made to relax its underlying utility-maximization premises which many feel are lacking behavioural realism ${ }^{1}$. Two assumptions that modellers have repeatedly tried to relax - mostly by adapting RUM-based models, rather than proposing completely new representations of the choice process - are the assumption of fully compensatory decision-making (e.g., Swait, 2001; Arentze and Timmermans, 2007) and the assumption of insensitivity to choice set-composition (e.g., Kivetz et al., 2004; Zhang et

\footnotetext{
${ }^{1}$ To address behavioural realism within decision making, some efforts are on attribute processing heuristics dealing with attribute non attendance (Scarpa et al, 2009; Cameron and De Shazo, 2010).
} 
al., 2004). Resulting models, however, are without exception less parsimonious and less tractable than RUM's workhorses, the (Mixed) Multinomial Logit models. Furthermore, they generally require researchers to develop specific-purpose code for estimation. Obviously, this hampers their broad applicability and restricts its use to specific circles of highly trained practitioners.

This paper presents a discrete choice-model paradigm that captures semi-compensatory decision-making and allows for choice set-composition effects, while remaining econometrically as parsimonious and tractable as RUM's (Mixed) Multinomial logit model. The model paradigm, called Random Regret Minimization (RRM), results in Logit-type choice probabilities and is estimable using conventional software-packages. It is based on the notion that when choosing, people aim to minimize future regret rather than aiming to maximize future utility - regret being defined as what one experiences when a non-chosen alternative performs better than a chosen one, on one or more attributes. There is much empirical evidence for this behavioural premise. Take for example Coricelli et al. (2005) who, using neuroimaging techniques, show that the area of the human brain that is active when decision-makers experience regret after having made a (poor) choice, is also highly active split seconds before they make a choice. In their words "anticipating regret is a powerful predictor of future choices".

Of course, the notion that regret is an important determinant of choice behaviour is not new, and is well established theoretically and empirically in many fields including marketing (e.g. Simonson, 1992; Zeelenberg and Pieters, 2007), microeconomics (e.g. Loomes and Sugden, 1982; Sarver, 2008), psychology (e.g. Zeelenberg, 1999; Connolly, 2005), the management sciences (e.g. Savage, 1954; Bell, 1982) and transportation (e.g., Chorus et al., 2006, 2009). What is new about the Random Regret Minimization-approach to Logit models is that it translates this conceptual notion of regret minimization into an operational, easily estimable, discrete choice model for the analysis of risky and riskless choices ${ }^{2}$. The RRM-approach to discrete choice modelling

\footnotetext{
${ }^{2}$ Note that although the RRM-paradigm shares with the well-known Regret Theory (RT - Loomes and Sugden, 1982; Loomes and Sugden, 1983; Quiggin, 1994) its consideration of regret as an important determinant of decisions, the two approaches differ on a number of aspects. Firstly, RT focuses on risky
} 
has been very recently introduced in transportation (Chorus, 2010) where it showed strong empirical potential - also when compared to its utilitarian counterparts - on a number of travel demand-datasets. Triggered by RRM's promising performance in a travel demand context, this paper theoretically and empirically explores RRM's potential for the field of environmental and resource economics.

Section 2 presents the RRM-based Multinomial logit model and provides a brief theoretical comparison with its utilitarian counterpart, the RUM-based Multinomial logit model. Section 3 presents a dataset concerning preferences for nature parks. Section 4 presents empirical analyses based on this dataset. More specifically, RRM and RUM are compared in terms of parameter estimates, goodness of fit and elasticities. Section 5 presents conclusions and avenues for further research.

\section{The RRM-approach to model decision-making}

Assume the following choice situation: a decision-maker faces a set of $J$ alternatives, each being described in terms of $M$ attributes $x_{m}$ that are comparable across alternatives. The focus is on predicting the choice probability for an alternative $i$ from this set. Before introducing the new RRM-based model, note as a reference point that a conventional, linear-additive utilitarian specification would assign the following deterministic utility to alternative $i: V_{i}=\sum_{m=1 . . M} \beta_{m} x_{i m}$. Adopting the classical RUM

choices and aims to capture choice-anomalies that are not being dealt with in neoclassical Expected Utility-theory, like preference reversals and common ratio effects. In contrast, while RRM may be extended towards the analysis of risky choice, it is primarily developed for the analyses of riskless choice and aims to capture semi-compensatory choice behavior and choice set-composition effects. Second, while RT is focused on the study of single-attribute choices (like monetary gambles), RRM is designed to model choice between multiattribute alternatives like those presented in Stated Choice-experiments. Third, while RT is a deterministic model, RRM is designed within the tradition of discrete choice theory and as such explicitly deals with unobserved preference heterogeneity by means of a random regret term. In combination, these conceptual differences translate into substantial differences in terms of mathematical model formulation and area of application. As a result, this paper will position RRM as a regret-based counterpart of RUM-theory, rather than a discrete choice-counterpart of Regret Theory. 
paradigm (that is: adding i.i.d. Extreme Value Type I-distributed errors to the deterministic utilities of all alternatives to represent heterogeneity in unobserved utility) implies the following MNL formulation of the resulting choice probability (McFadden, 1974): $P_{i}=\exp \left(V_{i}\right) / \sum_{j=1 . . J} \exp \left(V_{j}\right)$.

The RRM-based model postulates that, when choosing between alternatives, decisionmakers aim to minimize anticipated random regret, and that the level of anticipated random regret that is associated with the considered alternative $i$ is composed of an i.i.d. random error $\varepsilon_{i}$, which represents unobserved heterogeneity in regret and whose negative is Extreme Value Type I-distributed, and a systematic regret $R_{i}$. Systematic regret is in turn conceived to be the sum of all so-called binary regrets that are associated with bilaterally comparing the considered alternative with each of the other alternatives in the choice set: $R_{i}=\sum_{j \neq i} R_{i \leftrightarrow j}$. The level of binary regret associated with comparing the considered alternative with another alternative $j$ is conceived to be the sum of the regrets that are associated with comparing the two alternatives in terms of each of their $M$ attributes: $R_{i \leftrightarrow j}=\sum_{m=1 . . M} R_{i \leftrightarrow j}^{m}$. This attribute level-regret in turn is formulated as follows: $R_{i \leftrightarrow j}^{m}=\ln \left(1+\exp \left[\beta_{m} \cdot\left(x_{j m}-x_{i m}\right)\right]\right)$. This formulation implies that regret is close to zero when alternative $j$ performs (much) worse than $i$ in terms of attribute $m$, and that it grows as an approximately linear function of the difference in attribute-values in case $i$ performs worse than $j$ in terms of attribute $m$. In that case, the estimable parameter $\beta_{m}$ (for which also the sign is estimated ${ }^{3}$ ) gives the approximation of the slope of the regret-function for attribute $m$.

It is instructive at this point to note that this Logsum-formulation of attribute regret is a close approximation of the following function: $\max \left\{0, \beta_{m} \cdot\left(x_{j m}-x_{i m}\right)\right\}$. This latter function is in fact a more intuitive measure of attribute-level regret, as it postulates that

\footnotetext{
${ }^{3}$ Just like RUM-models, RRM-models easily allow for modeling random parameters, interaction effects and other sources of variability in parameters. One exception is the use of alternative-specific weights: since RRM is built around the notion that differences in attribute-values across alternatives generate regret, it assumes that the weight that is attached to this difference is generic across alternatives.
} 
regret equals zero when a considered alternative $i$ performs better than some other alternative $j$ on a particular attribute $m$, and that regret is a linear function of both the difference in attribute values and the importance of the attribute, when $i$ performs worse than $j$ on the attribute. However, what makes this formulation of attribute-level regret problematic is that the presence of the max-operator results in a kink when $\left(x_{j m}-x_{i m}\right)$ equals zero. This results in a non-smooth likelihood function for the RRM-model, which in turn creates difficulties with respect to the derivation of marginal effects and elasticities, and triggers a need for customized optimization routines to successfully estimate the model. The Logsum-formulation of attribute-level regret presented above circumvents this issue, as it smoothens the regret-function while providing a close approximation of $\max \left\{0, \beta_{m} \cdot\left(x_{j m}-x_{i m}\right)\right\}$. See Figure 1 for a visualization of this formulation of attribute-level regret (for the situations where $\beta_{m}=1,2$ and 3 respectively).

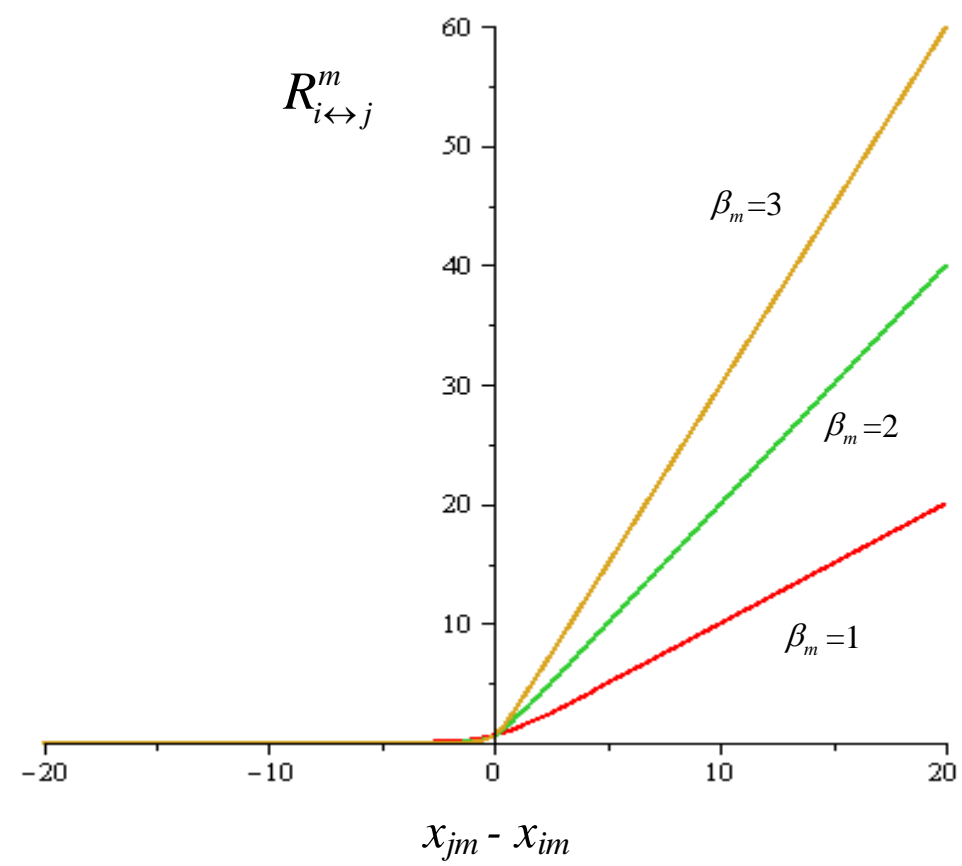

Figure 1: A visualization of attribute level-regret $R_{i \leftrightarrow j}^{m}=\ln \left(1+\exp \left[\beta_{m} \cdot\left(x_{j m}-x_{i m}\right)\right]\right)$ 
Systematic regret can then be written as: $R_{i}=\sum_{j \neq i} \sum_{m=1 . . M} \ln \left(1+\exp \left[\beta_{m} \cdot\left(x_{j m}-x_{i m}\right)\right]\right)$. Acknowledging that minimization of random regret is mathematically equivalent to maximizing the negative of random regret, choice probabilities may be derived using a variant of the well-known multinomial logit-formulation: the choice probability associated with alternative $i$ equals $P_{i}=\exp \left(-R_{i}\right) / \sum_{j=1 . . J} \exp \left(-R_{j}\right)$. Note that the obtained choice model can be easily coded and estimated using standard discrete choice-software packages.

The correspondence of the proposed RRM-based model with the linear-additive RUMbased model is striking: apart from the fact that both result in logit-choice probabilities, both models are equally parsimonious: each parameter estimated for a RRM-based model has a counterpart in a linear-additive RUM-based model. When choice sets are binary, the proposed RRM-based models and RUM-based models generate the same choice probabilities.

Apart from these similarities, the two modelling approaches exhibit a number of important differences - we briefly highlight two of those in this paper (see Chorus (2010)) for a more in-depth discussion of these differences, using numerical examples and formal proofs).

First, in contrast with conventional RUM-based models, the RRM-based model does not exhibit the IIA-property even when error terms are i.i.d. distributed. That is, the ratio of choice probabilities of any two alternatives $i$ and $j$ depends on the performance of these alternatives relative to one another as well as relative to each other alternative $k$ in the set. This follows directly from the specification of the regret-function, which postulates that the regret associated with any alternative in the set is a function of its performance relative to each of the other alternatives available. Second, in contrast with linearadditive utilitarian choice-models, the model based on regret minimization implies semi-compensatory behaviour. This is a direct result of the convexity of the regretfunction depicted in Figure 1: improving an alternative in terms of an attribute on which it already performs well relative to other alternatives generates only small decreases in 
regret, whereas deteriorating to a similar extent the performance on another equally important attribute on which the alternative has a poor performance relative to other alternatives may generate substantial increases in regret. As a result, the extent to which a strong performance on one attribute can make up for a poor performance on another depends on the relative position of each alternative in the set. This results in a choice set composition-effect which has been well established empirically in the field of consumer choice (e.g. Kivetz et al., 2004), called the compromise effect. This effect states that alternatives with an 'in-between' performance on all attributes, relative to the other alternatives in the choice set, are generally favored by choice-makers over alternatives with a poor performance on some attributes and a strong performance on others.

It is worth emphasizing at this point, that RRM's ability to display semi-compensatory decision-making and choice set-effects like the compromise effect does not come at the cost of added parameters like is the case in other models that aim at capturing these behavioral phenomena. In contrast, in the context of the RRM-model, these behavioral phenonoma emerge from the underlying structure which itself follows directly from the model's single underlying behavioral premise (that decision-makers aim to avoid the situation where a non-chosen alternative performs better than a chosen one in terms of one or more of its attributes). This implies that RRM is parsimonious and easy to estimate when compared to many other non-RUM models aiming to capture semicompensatory behavior and/or choice set-composition effects: as said earlier, RRM in its most basic form consumes no more parameters than RUM's linear-additive MNLmodel and it can be estimated using standard discrete choice-software packages.

Following its recent introduction, RRM-based model has been shown to perform well empirically (in terms of model fit and predictive ability) when compared to equally parsimonious RUM-based counterparts on a number of choice situations, including choices among shopping destinations, parking lots, mode-route combinations, departure times, car-types and even online dating-profiles (Chorus, 2010; Chorus and Rose, 2011; Chorus and de Jong, 2011; Hensher et al., forthcoming). Differences in model fit are generally small but statistically significant when put to the Swait and Ben-Akiva (1986) test for non-nested models. More important than these small differences in fit is perhaps 
the finding that significance levels of parameters as well as parameter ratios and elasticities may differ more substantially between model-specifications, implying sometimes quite differing policy- and planning-implications. In the next sections, RRM and RUM will be compared using a dataset collected in an Italian nature park, involving Stated Choices between different recreational opportunities in that park. In keeping with the above discussion, we will focus on differences and similarities between the two models in terms of their outcomes and managerial implications, rather than on their fit with the data (as we will see these differences in fit are small, which is in line with findings from previous studies).

\section{The site}

The site of interest is the Natural Park of the Ampezzo Dolomites located in the heart of the Dolomites, which are mountains in the eastern Alps (Italy). In 2009 they were included in the World Heritage List due to their unique landscape and their scientific importance for the geological and geomorphological aspects. The Park covers an area of 11,000 hectares surrounding the town of Cortina d'Ampezzo. The landscape is quite articulated with impressive peaks and massive rocks on the skyline. From a geological point of view, the mountain rocks have a sedimentary origin which dates back to 200 million years ago and it is mostly made up by dolomite and limestone The dramatic scene created by pink-orange reflections of the rocks at sunset, for which these mountains are world-renown, is due to such geological features.

From an ecological point of view, the Park of the Ampezzo Dolomites is characterized by a rich variety of habitats: forests, grasslands and watersheds provide a very heterogeneous development of floral and animal species. In terms of land use, there are managed woodlands and other less intensively managed areas set aside as nature reserves $(25 \%)$, so to preserve the best and most pristine parts. The park, which is probably the most visited protected area of the eastern Alps, is characterized by environmental amenities and logistic services appreciated by different groups of users. There is an extended network of forest trails and other established walkways, which 
extend to up to $350 \mathrm{~km}$ in length and include via ferrata and equipped trails, some of which have high historical value since they were established as mountain roads in the frontline during World War I. An interesting feature of the natural park is that it is managed by the Regole d'Ampezzo, which are composed by local family communities who own the land as ancient land-managing bodies. Since early settlers, they administrated and managed jointly pastures and forests in order to preserve natural heritage.

\section{The survey and the experimental design}

The Natural Park of the Ampezzo Dolomites, as other alpine park agencies, typically faces controversial decisions in terms of land management. On one hand the aim is to preserve the land and the ecosystem, whereas on the other hand the focus is on the provision of services to facilitate different groups of users. Visitors are in fact engaged in various types of recreational activities and show increasing expectations for highquality outdoor experiences. The park management was interested in investigating and capturing heterogeneous preferences of visitors in order to implement environmental and management policies on the basis of strategically collected information. To this extent the knowledge of attitudes and preferences towards a selection of services that could be provided becomes particularly important.

Using an alternative approach that adds in terms of better understanding visitors' decision making process would be of help to manage outdoor recreation. Rather than focusing exclusively on the maximization of utility when visitors choose among alternatives with common attributes, RRM offers a behavioural choice rule based on minimizing anticipated regret. This would allow park management decisions to be informed by potential regret associated with the wish of avoiding the "wrong" choice experienced by visitors.

Data were collected via face-to-face on site interviews of visitors during the summer 2008 in the Natural Park of the Ampezzo Dolomites. Data from focus groups and a pilot study was used to calibrate the survey instrument at the beginning of the good season. 
The target population was composed by visitors interested in outdoor recreation, hence respondents were intercepted at the end of their visit as they went back to the car park. Respondents were randomly sampled within five categories of visitors depending on the main purpose of the visit of the day. Locations to approach respondents were chosen in relation to the specific outdoor activity. Depending on the number of recreationists transiting, interviewers approached one visitor and asked him or her to take part in the interview. The exact number of people that was approached depended on the category of visitors and the day of the week. Based on suggestions by the park's management, who were interested in focusing on a stratified sample in order to take into account the needs of specific groups of users, the following five categories of visitors were selected: (1) hikers, (2) climbers, (3) mountain bikers, (4) visitors who mainly use via-ferratas ${ }^{4}$ and (5) visitors who were engaged in short walks and/or picnicking. To ensure a full balanced design 96 respondents were interviewed for each of the five strata, so that a total of 480 surveys were collected and completed to balance the design.

The management was fully involved in the selection of the attributes and the levels, because of their interest in information aimed at implementing strategic management policies. A total of ten attributes were selected and each attribute had three possible levels. Some of the attributes were of general interest to all five outdoor groups, while others were more category-specific. The list of the attributes and their levels is reported in tables 1, whereas Table 2 provides the description of the attributes used in the estimation and the list of acronyms. These included the building of additional five and seven thematic itineraries specifically dealing with historical aspects, flora and fauna (ITINERARIES). Rare flower species grow in the area and military fortifications and trails originally built and used to service the frontline in World War I are still in use to reach vantage points. There is currently a dense net of hiking trails within the boundaries of the park $(350 \mathrm{~km})$, and the management board was interested to find out

\footnotetext{
${ }^{4}$ Via-ferrata are challenging trails that allow to access vantage points or the top of a mountain in order to enjoy viewscapes. They are usually characterized by a prominent slope and because of the steepness, special equipment is needed to go along via-ferrata. This equipment involves gear to fasten oneself to an iron-cable anchored to the rock or other secure places. In terms of skills required of the visitor, this type of activity can be placed between sport climbing and the traditional hiking.
} 
visitors' preferences for an increase to $400 \mathrm{~km}$ or a decrease to $300 \mathrm{~km}$ (TRAILS). The system of trail signs is also a relevant attribute for most of the visitor typologies, since it provides information about directions to all. It is based on both vertical and horizontal sign system, where the first category makes use of board signs usually located at trail junctions and the second relies on red and white marks painted on stones along the trails. The attribute levels are based on a mix of the presence and the frequency of the signs along the path (TRL_SIGNS). Vertical signs at junctions plus paint marks every $200 \mathrm{mt}$ along the trail and vertical signs at junctions plus paint marks every $50 \mathrm{mt}$ are contrasted with the baseline that is vertical boards at the junctions only.

As visitors may be interested in different types of trails, the provision of selected managed paths was investigated (MNGD_TRAILS_EXCURSION). The park management was keen to build new itineraries based on technical challenge, length and effort by taking into account the length of paths and the slope of the land. Therefore, attribute levels included new itineraries of 3 and 6 hours. A specific attribute for climbers was proposed, namely the provision of additional climbing itineraries in crags and cliffs (CLIMBS). Accordingly, 20 climbing routes, 40 and 60 climbing itineraries were set as attribute levels. Improvements of safety features of via ferratas were investigated. Attribute levels concern structural and technical aspects as iron cable necessary only along part of the path (baseline), iron cable along the whole path (FERRATA_N1) and iron cable along the whole path plus artificial holds (FERRATA_N2). Alpine shelters (SHELTERS) are common and quite important because they provide refuge in case of bad weather conditions and they offer local food. Based on the current availability of alpine shelters (23 units), the depicted scenario considered an increase of three alpine shelters or a decrease of three.

Congestion was definitely a relevant issue to the park management, and particularly the way this was perceived by visitors. Different levels of congestion were described to visitors on the basis of the number of encounters made while walking the trails (CROWD): less than 20 people, between 20 and 50 people, more than 50 people. The park's management was also interested to estimate visitors' preference towards the availability of park information. As a consequence, a leaflet providing basic information 
about the park was compared with a brochure with additional information (INFO1), and a book with an extended description of the flora, fauna and historical aspects of the protected area (INFO2). Ultimately, to explore visitor's sensitivity to money an entrance fee was considered. This was the only attribute with four levels, namely $€ 2, € 5, € 7$, and $€ 10$. Although no entrance fee is currently required, the park management was particularly interested in this scenario: first, such a fee is already implemented in similar contexts and second, public funds provided by institutions are rapidly decreasing. For the purpose of the analysis, the attributes itineraries, trails, managed trails, trail signs, climbing itineraries, shelters, crowd and cost were numerically coded, whereas the remaining were dummy coded. The coding of the baseline was chosen for each attribute so as to represent the attribute levels of the status quo (SQ) condition. More specifically, the SQ option (Neither option) implies that all attributes take their status quo level.

At this point it is interesting to note that RRM may be expected to have a somewhat weaker performance when a 'no-choice' option is presented to respondents. This follows from the fact that RRM is designed to predict choices between alternatives that are comparable across relevant attributes - it is exactly this comparison of alternatives in terms of each of their common attributes which generates regret. RRM has little to say about the situation where alternatives do not share most or all of their attributes, like is the case when a 'no-choice'-option is present. Although the RRM-model remains estimable in these situations by means of estimating a constant for the 'no choice'option, it is expected that RRM's MNL is likely to be outperformed in terms of model fit by RUM's MNL, when a 'no choice'-option is present. In this paper, this issue is partly avoided by framing the 'no choice'-option as the status quo, which implies that for this status quo attribute-levels can be defined. However, it should be noted that respondents to our survey were not presented with these implied attribute-values of the status quo option, so that a comparison with the attribute-values of alternatives A and B (the 'choice'-options) remains difficult and implicit. As a result, one would not expect a particularly strong performance of RRM on the data generated by our survey, when compared to data from choice experiments that do not involve 'no choice'- or status quo-options. 
Four different waves for each of the five groups of visitors characterized the overall survey design. At the end of each wave two attributes were excluded on the basis of results obtained from a basic MNL model that was estimated on cumulated sample of the collected data. MNL results were used as priors for the derivation of the WTP efficient design (Scarpa and Rose 2008) of the subsequent waves. In this fashion, the design survey for the first sample included all ten attributes (nine plus the cost) and was the same across all groups of visitors. In each subsequent wave, the attributes with significant coefficients or less relevant for specific group of visitors (for example climbers or mountain-bikers) were excluded from further investigations. The aim of the strategy was that attributes with least accurate parameter estimates could be evaluated by a larger sample size of respondents. Samples in later waves could also dedicate more attention to attribute evaluation because they were progressively presented with fewer attributes describing each alternative.

Excluded attributes are reported in table 3 . The second wave had seven attributes plus the cost, the third five plus the cost and the last one three plus the cost. A specific WTP $_{\mathrm{b}}$-efficient design was used for each sample wave (Ferrini and Scarpa, 2007; Vermeulen et al. 2010). Subscript "b" denotes Bayesian priors, that is for each wave and each sample group the $\mathrm{WTP}_{\mathrm{b}}$-efficient design was estimated by means of information collected in the previous wave (Scarpa et al., 2007). This allowed us to fully exploit the features of the efficient Bayesian design. More specifically, it allowed us to update the information contained in the design, by focussing on the specific characteristics of a single category of visitors. Besides considering a parameter's mean value, a Bayesian design also incorporates the variance of a parameter and by doing so it addresse the uncertainty of the estimates which in turn is linked with the sample size. Priors for the first wave were instead derived from the pilot survey. Within each sample group and each wave 24 visitors were surveyed and each of them was presented with 12 choice tasks for an overall balanced sample of 480 completed surveys. In the first wave the efficient design consisted of 72 choice tasks that were blocked into six groups, in the second wave there were 36 choice tasks blocked into three, the third one had 24 choice tasks blocked into two and the last one had only 12 choice tasks. Table 4 provides an example of a choice task for the first wave. 


\section{Empirical comparison between RUM and RRM}

RUM-based and RRM-based multinomial logit-models were estimated and results are reported in Table 5. Based on a Ben-Akiva and Swait test for non-nested models (1986) the difference in final log-likelihood values is statistically significant at a $1 \%$ significance level, which indicates that the random utility model performs better in terms of statistical fit, than the random regret one ${ }^{5}$. Nevertheless, the difference in fit remains small, as indicated by the two models' rho-square ( 0.083 for RUM, 0.080 for RRM). All parameters show the expected signs and most of them are statistically significant at a $10 \%$ significance level, with a few exceptions. In particular, the latter are the number of climbs (CLIMBS), the highest level of safety along via-ferrata (FERRATA_N2) and brochure and/or books with a detailed description of the site (INFO1 and INFO2).

Following the description, in section 2, of the theoretical foundation of RRM, parameters estimated through the two paradigms deserve a different interpretation and cannot be straightforward compared. In the traditional RUM setting the overall utility of an alternative can be computed by taking into account the specific contribution of each attribute and the associated parameter estimate. This means that the availability of different types of trails, as for example hiking paths (TRAILS) or thematic itineraries that focus on flora, fauna and historical aspects (ITINERARIES), increases the utility associated with that alternative. Moreover, visitors are more likely to appreciate a high presence and frequency of signs along the path (TRL_SIGNS), such as vertical signs at junction plus paint marks rather then vertical boards only. Alpine shelters play a relevant role in offering local food and providing refuge in case of bad weather conditions. On the other hand, a high level of congestion (CROWD) decreases the overall utility, as well as more technical and structural aspects concerning challenging paths as via ferrata (FERRATA_1, FERRATA_2). Quite differently, in a RRM-setting

\footnotetext{
${ }^{5}$ It may be noted that on the subsample of choices made by mountainbikers $(\mathrm{N}=1152)$, the RRM-model did significantly outperform its RUM-based counterpart - however, in the remainder of the analyses we focus on the entire sample of choice observations.
} 
parameters reflect the upper bound of the extent to which a unit in- or decrease in relative performance on an attribute influences regret. Whether or not this upper bound is reached for a one unit in- or decrease in an attribute's value depends on the performance of other alternatives in the set in terms of the attribute.

A more direct comparison of preferences and tastes can be established by using parameter estimates to derive direct choice elasticities ${ }^{6}$. Direct choice elasticities derived in the RUM as well as in the RRM context provide a measure of the relationship between a one percentage change in the level of the attribute and the percentage change in the probability of choosing the alternative characterized by that specific attribute. It is worth emphasizing that, differently from RUM, RRM-based direct elasticities associated with a change in an alternative's attribute depend on the relative performance of all the alternatives in the choice-tasks, rather than depending only on the performance (choice probability) of the specific alternative. This follows directly from the behavioural premise, underlying the RRM-approach, that the regret associated with an alternative's attributes depends on its performance on these attributes relative to the performance of other alternatives on these attributes.

Direct elasticity values ${ }^{7}$ and relative differences obtained within RUM and RRM paradigms are reported in table 6 (for attributes with significant parameters only). Since the experimental design was based on unlabelled alternatives, mean values of the relative differences for the two alternatives (alternative A and B) are computed and reported. It would not add information to discuss differences in direct elasticities for alternative A and B separately, since there are no intrinsic differences between the two choice options (furthermore, in line with this argument, in the case at hand these differences were found to be very small). As can be noted (see column 2 and 3 in Table 6) values of the two options look pretty similar when expressed in terms of their absolute levels. Differences become apparent when one inspects elasticity-ratios (RUM-

\footnotetext{
${ }^{6}$ See Hensher et al., submitted, for the formal derivation of elasticities in the context of an estimated RRM-model. Note that a routine is available in NLOGIT to compute RRM-based elasticities.

${ }^{7}$ Arc and point elasticity values are computed for dummy and numerically coded variables respectively. The latter are itineraries, trails, trail signs, managed trail excursions, climbing itineraries, shelter, crowd and cost.
} 
elasticity divided by RRM-elasticity). Six out of eight attributes turn out to be more elastic in a RRM-context than in a RUM-context., The attribute 'safety features on viaferrata' and the entrance fee are substantially more elastic in a RUM-context. In general, most of the attributes are relatively inelastic, with the exception of the entrance fee.

To highlight the relevance of the model outputs in terms of managerial implications in the context of predicting changes in the probability of visiting the site, an environmental policy scenario was explored. Differences in the results of the two paradigms would be particularly noteworthy here, considering the importance of adequately assessing the variation of choice probabilities. The entrance fee is among the most interesting attributes for a policy maker in terms of management of a natural park, in the light of the progressively decreasing availability of funds provided by local and national governments. The policy scenario therefore involves an increase of the entrance fee by $15 \%$ in order to simulate the implied changes in the proportion of visitors that are willing to pay an entrance fee in order to access the site. Results obtained from the two choice-paradigms are reported in Table 7 for comparison. Increasing the access fee to the Natural Park of the Ampezzo Dolomites implies a decreased probability of selecting the alternative involving the cost raise (affected alternative), and, more interestingly, an increased probability of choosing the status quo, that is the probability of not being willing to pay the entrance fee. It is easily seen that RUM- and RRM-based models predict different changes in resulting choice probabilities: the impact of the raise in entrance fee that is predicted by the RRM-based model is only two-third of the impact that is predicted by the RUM-based model.

There is no direct and straightforward conceptual relation between on the one hand conceptual differences between RRM and RUM, and on the other hand differences between the two approaches in terms of elasticities or predicted changes in choice probabilities resulting from policy interventions. What is more interesting, perhaps, is to note that while these two models have similar model fit and are equally parsimonious in terms of parameters requiring estimation, they can generate sometimes substantially different managerial implications. This finding is in line with results reported in Hensher et al. (forthcoming), where an RRM-model and its RUM-counterpart also 
hardly differ in terms of model fit (in that case the RRM-model significantly outperforms the RUM-model), while producing sometimes markedly different elasticities.

\section{Conclusions and discussion}

This paper presented a Random Regret Minimization (RRM)-approach to discretechoice modelling of stated preference data on natural park services. RRM is a regretbased counterpart of the well-known RUM-based approach. RRM-models result in closed-form logit type choice probabilities, and are suitable for the analysis of risky and riskless choices between multiattribute alternatives in multinomial choice contexts. They are easily estimable using conventional discrete choice-software packages and as such provide the first operational and integrative regret-based discrete choice models to date. Their main distinguishing feature when compared to conventional RUM-models such as the equally parsimonious linear-additive MNL-model is that RRM-models display semi-compensatory choice-behaviour and allow for choice set composition effects.

Triggered by recent empirical evidence of a strong performance of RRM in the context of travel demand modelling (destination-choice, mode-choice, route-choice, departure time-choice, and car-type choice), this paper explores RRM's suitability in the context of environmental and resource economics-based decision-making. Using a stated choice dataset concerning choices between different nature parks, models of both types (RUM and RRM) are estimated and their results are compared. On the available data, the RUM-specification results in a better model fit in a statistical sense, although the difference with RRM is very small. It is also found that important model outputs, such as elasticities and choice probability forecasts, may differ more substantially between the two choice-modelling paradigms despite a similar fit with the underlying choice data. 
The results presented here echo closely those reported in other recent papers in transportation and beg the question of what may be the outlook for the RRM-approach in the field of environmental and resource economics.

There are several dimensions to the answer to this question: first, it is worthwhile to have a look at what literature from the field of social-psychology has to say about regret-minimization. A review written by Zeelenberg and Pieters (2007) mention that regret-minimization has been found to be a particularly important choice behaviour when choices are perceived as important and difficult, when the decision-maker expects to receive feedback about chosen and non-chosen options in the short term, and when he or she believes that he or she will be held accountable for his or her choices. Extrapolating these notions to the field of environmental and resource economics, it seems that there are ample choice situations that match the abovementioned conditions. In those situations, it may be expected that the RRM-approach to discrete choice modelling will perform well.

Apart from this targeted application of RRM to regret-prone situations, its ease of estimation might also make it worthwhile to estimate RRM-based models as a secondopinion alternative to the conventional RUM-based approach. In light of the fact that RRM's underlying behavioural premises are fundamentally different from those underlying RUM-theory, one may test whether managerial implications obtained from RUM-based analyses also hold in the context of a RRM-based model. If they do, this may be considered a sign of their robustness. Finally, it seems reasonable to adopt a more hybrid approach: while some combinations of decision-maker-characteristics and decision-contexts may result in behaviour that is better captured by a RUM-based model, other combinations may better fit RRM-predictions. Take for example the subsample of mountain bikers, which resulted in a statistically significant better fit for the RRM-based model, while estimation on the other four visitor categories resulted in a better fit for the RUM-specification. Furthermore, there may even be differences at the level of attributes: while some attributes may be processed in a utility-maximization fashion, others may be processed in a way more consistent with regret-minimization or in both ways. 
At this point it is worth mentioning that in this paper, we have mainly focused on RRM's potential as a choice model, and on how it differs from RUM in terms of estimation results, elasticities and predicted choice probabilities. As such, the dimension of valuation, which is of great importance in the field of environmental and resource economics, has not been addressed here. Without going into too much depth here for reasons of space limitations, a few comments can be made about RRM's potential in terms of providing useful valuation-output. Firstly, although RRM-based Willingnessto-Pay (WtP) measures can be derived by means of taking the ratio of relevant partial derivatives of the regret-function, these measures are not solidly rooted in microeconomic axioms in the way RUM-based measures of WtP are. For example, as is shown in Chorus (in press), RRM-based WtP-measures are sensitive to changes in the performance of all available alternatives in terms of the cost-attribute and the attribute for which WtP is estimated. Clearly, although this property may be realistic from a behavioral point of view, it creates difficulties when it comes to the translation of WtP into well-behaved demand functions. Second, and for similar reasons, it is difficult to translate the amount of regret associated with a particular choice situation into a monetary value. As is well-known, this translation is relatively straightforward and intuitive in a RUM-context, leading to insightful measures of consumer surplus. Although recent work suggests that fairly reasonable measures of consumer surplus can be obtained by combining RUM- and RRM-output (Chorus \& de Jong, 2011), these measures are invariably less intuitive (more complicated) than the relatively easy to interpret Logsum-notion.

In sum, the translation of regret into monetary values is not as intuitive as is the case for utility. Nonetheless, some progress is being made in this regard. In fact, this issue touches upon the more general notion, increasingly highlighted in the choice-modeling community, that in order to arrive at meaningful and well-behaved tools for valuation, one often needs to rely on models that are restrictive in terms of their behavioral assumptions. For example, although choice set-composition effects have been found to be very important determinants of choice-behavior, capturing them in choice-models almost by definition causes a loss in the model's ability to generate well-behaved WtP and consumer surplus-measures. In other words, in order for our models' outcomes to 
be well-behaved, we often need to ignore that in real life, human decision-makers are generally not that 'well-behaved' when making choices. It will obviously depend on the planning problem at hand which modeling strategy should best be adopted. Sometimes, a 'well-behaved' model is needed, whereas in other situations, a model that is able to capture some behavioral 'anomalies' might be preferred. The RRM-approach may be a good candidate when the latter situation arises.

As will have become clear by now, the development of RRM into becoming a fullfledged econometric toolbox for the analyses of choice behavior is very much work-inprogress. However, it may be expected that in the near future, after having put additional effort in theorizing and in empirical analyses, answers will be found. We hope that in time these answers will help identify under what conditions the RRMapproach may help advance our understanding of decision-making in the field of environmental and resource economics.

\section{Acknowledgements}

Support from the Netherlands Organization for Scientific Research (NWO), in the form of VENI-grant 451-10-001, is gratefully acknowledged by the third author. The first author wishes to acknowledge the Natural Park of the Ampezzo Dolomites for funding. Very useful suggestions made by an anonymous referee were instrumental in improving an earlier version of this paper.

\section{References}

Arentze, T.A., Timmermans, H.J.P., 2007. Parametric action trees: incorporating continuous attribute variables into rule-based models of discrete choice. Transportation Research Part B, 41(7), pp. 772-783 
Beharry-Borg, N., Hensher, D.A., Scarpa, R., 2009. An analytical framework for joint versus separate decisions by couples in choice experiments: The case of coastal water quality in Tobago. Environment and Resource Economics, 43, pp. 95-117

Bell, D.E., 1982. Regret in decision making under uncertainty. Operations Research, 30(5), pp. 961-981

Ben-Akiva, M., Lerman, S.R., 1985. Discrete choice analysis: theory and application to travel demand. The MIT Press, Cambridge, Mass

Ben-Akiva, M.E., Swait, J., 1986. The Akaike likelihood ratio index. Transportation Science, 20(2), pp. 133-136

Bullock, C.; Elston, D. and Chalmers, N. 1998. An application of economic choice experiments to a traditional land use deer hunting and landscape change in the Scottish Highlands. Journal of Environmental Management, 52, pp. 335-351

Cameron, T.A. and De Shazo J.R. 2010. "Differential Attention to Attributes in Utilitytheoretic Choice Models" Forthcoming in Journal of Choice Modeling.

Campbell, D., Hutchinson, W.G., Scarpa, R., 2008. Incorporating discontinuous preferences into the analysis of discrete choice experiments. Environment and Resource Economics, 41, pp. 401-417

Campbell, D.; Hutchinson, W. G.; Scarpa, R.; Birol, E. and Koundouri, P. (ed.), 2008. Using mixed logit models to derive individual-specific WTP estimates for landscape improvements under agri-environmental schemes: evidence from the Rural Environment Protection Scheme in Ireland 3 Choice experiments informing Environmental Policy, Edward Elgar, pp. 58-81

Chorus, C.G., 2010. A new model of Random Regret Minimization. European Journal of Transport and Infrastructure Research, 10(2), pp. 181-196

Chorus, C.G., in press. Random Regret Minimization: An overview of model properties and empirical evidence. Transport Reviews. 
Chorus, C.G., Molin, E.J.E., van Wee, G.P., Arentze, T.A., Timmermans, H.J.P., 2006. Responses to transit information among car-drivers: Regret-based models and simulations. Transportation Planning and Technology, 29(4), pp. 249-271

Chorus, C.G., Arentze, T.A., Timmermans, H.J.P., 2009. Spatial choice: A matter of utility or regret? Environment and Planning Part B, 36(3), pp. 538-551

Chorus, C.G., de Jong, G.C., 2011. Modeling experienced accessibility for utilitymaximizers and regret-minimizers. Journal of Transport Geography, 19(6), 1155-1162

Chorus, C.G., Rose, J.M., 2011. Selecting a date: A matter of regret and compromises. Paper accepted for presentation at the $2^{\text {nd }}$ International Choice Modeling Conference, Leeds, UK

Connolly, T., Reb, J., 2005. Regret in cancer-related decisions. Health Psychology, 24(4), pp. 29-34

Coricelli, G., Critchley, H.D., Joffily, M., O’Doherty, J.P., Sirigu, A., Dolan, R.J., 2005. Regret and its avoidance: A neuroimaging study of choice behaviour. Nature Neuroscience, 8(9), pp. 1255-1262

DeShazo J. R., Cameron T.A., Saenz M. 2009. The Effect of Consumers' Real-World Choice Sets on Inferences from Stated Preference Surveys, Environmental and Resource Economics, 42, pp.319-343.

Ferrini, S. and R. Scarpa, 2007. Designs with a-priori information for nonmarket valuation with choice-experiments: a Monte Carlo study. Journal of Environmental Economics and Management, 53, pp. 342-363.

Hanley, N.; Wright, R. and Koop, G., 2002. Modelling Recreation Demand Using Choice Experiments: Climbing in Scotland. Environmental and Resource Economics, 22, pp. $449-66$ 
Hearne, R. R. and Salinas, Z. M., 2002. The use of choice experiments in the analysis of tourist preferences for ecotourism development in Costa Rica. Journal of Environmental Management, 65, pp. 153-163

Hensher, D.A., Greene, W., Chorus, C.G., Forthcoming. Random Regret Minimisation or Random Utility Maximisation: An exploratory analysis in the context of automobile fuel choice. Journal of Advanced Transportation

Hensher, D.A., Beck, M.J., Rose, J.M., 2011. Accounting for preference and scale heterogeneity in establishing whether it matters who is interviewed to reveal household automobile purchase preferences. Environment and Resource Economics, 49 (1), pp. 122.

Herriges JA, Phaneuf DJ. 2002. Inducing patterns of correlation and substitution in repeated logit models of recreation demand. American Journal of Agricultural Economics, 84(4), pp. 1076-1090

Kivetz, R., Netzer, O., Srinivasan, V., 2004. Alternative models for capturing the compromise effect. Journal of Marketing Research, 41, pp. 237-257

Johnston, R., Duke, J. M., 2007. Willingness to Pay for Agricultural Land Preservation and Policy Process Attributes: Does the Method Matter?, American Journal of Agricultural Economics, 89, pp. 1098-1115

Loomes, G., Sugden, R., 1982. Regret-Theory: An alternative theory of rational choice under uncertainty. The Economic Journal, 92(368), pp. 805-824

Loomes, G., Sugden, R., 1983. A rationale for Preference Reversal. American Economic Review, 73(3), pp. 428-432

McFadden, D., 1974. Conditional logit analysis of qualitative choice-behaviour. In Zarembka, P., (Ed.) Frontiers in econometrics, Academic Press, New York

Meyerhoff, J., Ohl, C., Hartje, V., 2010. Landscape externalities from onshore wind power, Energy Policy, 38, pp. 82-92 
Morey, E., Thacher, J., Breffle, W. 2006. Using angler characteristics and attitudinal data to identify environmental preference classes: a latent-class model. Environmental and Resource Economics 341, pp. 91-115.

Morey E., and Thiene M., submitted, A parsimonious, latent-class methodology for predicting behavioural heterogeneity in terms of life-constraint heterogeneity.

Quiggin, J., 1994. Regret theory with general choice sets. Journal of Risk and Uncertainty, 8(2), pp. 153-165

Savage, Leonard J., 1954. The Foundations of Statistics. New York: Wiley

Scarpa R., T. J. Gilbride, D. Campbell and D. A. 2009. Hensher, Modelling attribute non-attendance in choice experiments for rural landscape valuation. European Review of Agricultural Economics, 36(2), pp.151-174

Scarpa, R. and J. M. Rose. 2008. "Design efficiency for non-market valuation with choice modelling: how to measure it, what to report and why." Australian Journal of Agricultural and Resource Economics 52, pp. 253-282

Scarpa R., Thiene M., Train K. 2008. Utility in WTP space: a tool to address confounding random scale effects in destination choice to the Alps, American Journal of Agricultural Economics, 90(4), pp. 994-1010

Scarpa, R., D. Campbell and W. G. Hutchinson. 2007. "Benefit estimates for landscape improvements: sequential Bayesian design and respondents' rationality in a choice experiment study." Land Economics, 83(4), pp. 617-634.

Scarpa R., Thiene M., 2005. Destination choice models for rock-climbing in the NorthEastern Alps: a latent-class approach based on intensity of preferences, Land Economics, 85(3), pp. 426-444

Simonson, I., 1992. The influence of anticipating regret and responsibility on purchasing decisions. Journal of Consumer Research, 19(1), pp. 105-119 
Sarver, T., 2008. Anticipating regret: Why fewer options may be better. Econometrica, 76(2), pp. 263-305

Swait, J., 2001. A non-compensatory choice model incorporating attribute cutoffs. Transportation Research Part B, 35, pp. 903-928

Thiene M., Scarpa T. 2008. Hiking in the Alps: exploring substitution patterns of hiking destinations, Tourism Economics, 14(2), pp.263-282

Thiene, M., Scarpa, R., 2009. Deriving and testing efficient of WTP distributions in destination choice models. Environment and Resource Economics, 4, pp. 379-395

Train, K. E., 2009. Discrete choice methods with simulation, 2nd edition. Cambridge University Press, Cambridge (MA, USA)

Vermeulen, B., Goos, P., Scarpa, R. and Vandebroek, M. L., 2010. Conjoint Choice Designs to Measure the WTP. Forthcoming in Environmental and Resource Economic

Zeelenberg, M., 1999. The use of crying over spilled milk: A note on the rationality and functionality of regret. Philosophical Psychology, 12(3), pp. 325-340

Zeelenberg, M., Pieters, R., 2007. A theory of regret regulation 1.0. Journal of Consumer Psychology, 17(1), pp. 3-18

Zhang, J., Timmermans, H.J.P., Borgers, A., Wang, D., 2004. Modelling traveler choice behavior using the concepts of relative utility and relative interest. Transportation Research Part B, 38(3), pp. 215-234 
Table 1 - Attributes and levels.

\begin{tabular}{|c|c|c|c|}
\hline Attribute & Attribute levels & Attribute & Attribute levels \\
\hline \multirow[t]{3}{*}{ Thematic itineraries (n) } & $2 *$ & Via ferrata & Iron cable along part of the path* \\
\hline & 5 & & Iron cable along the whole path \\
\hline & 7 & & Iron cable plus artificial holds \\
\hline \multirow[t]{3}{*}{ Network of trails $(\mathrm{km})$} & 300 & Shelters (n) & 17 \\
\hline & $350 *$ & & $20 *$ \\
\hline & 400 & & 23 \\
\hline \multirow[t]{3}{*}{ Trail signs } & Vertical signs* & Congestion (n) & $<20 *$ \\
\hline & Vertical signs plus horizontal painted signs 200 & & $20-50$ \\
\hline & Vertical signs plus horizontal painted signs 50 & & $>50$ \\
\hline \multirow[t]{3}{*}{ Managed trails excursions (hours) } & $1 *$ & Information & Leaflet* \\
\hline & 3 & & Brochure \\
\hline & 6 & & Book \\
\hline \multirow[t]{5}{*}{ Climbing routes $(\mathrm{n})$} & $20 *$ & Entrance fee $(€)$ & $0 *$ \\
\hline & 40 & & 2 \\
\hline & 60 & & 5 \\
\hline & & & 7 \\
\hline & & & 10 \\
\hline
\end{tabular}

* Status quo level 
Table 2 - Attributes used in the estimation.

\begin{tabular}{|c|c|c|}
\hline Attribute & Acronym & Variable description \\
\hline Thematic itineraries & ITINERARIES & Thematic itineraries focusing on flora, fauna and historical aspects. Building of 5 and 7 itineraries $(5,7)$ \\
\hline Network of trails & TRAILS & Network of trails and hiking paths. Decrease to $300 \mathrm{~km}$ and increase to $400 \mathrm{~km} .(300,400)$ \\
\hline Trail signs & TRL_SIGNS & Vertical signs at junctions plus horizontal painted signs every $200 \mathrm{mt}$ and every $50 \mathrm{mt}$ along the path \\
\hline Mngd trails excursions & MNGD_TRAILS_EXCURSIONS & Technical challenge itineraries. Building of 3 hours and 6 hours itineraries $(3,6)$ \\
\hline Climbing routes & CLIMBS & Climbing itineraries along cliffs and crags. Building of 40 and 60 climbing routes $(40,60)$ \\
\hline \multirow[t]{2}{*}{ Via ferrata } & FERRATA_N1 & Iron cable along the whole path \\
\hline & FERRATA_N2 & Iron cable along the whole path plus artificial holds \\
\hline Shelters & SHELTERS & Alpine shelters. Decrease of 3 shelters and increase of 3 alpine shelters $(17,23)$ \\
\hline Congestion & CROWD & Number of people met along the trails $(35,100)$ \\
\hline \multirow[t]{2}{*}{ Information } & INFO1 & Brochure providing little more than basic information of the area \\
\hline & INFO2 & Book containing an extended description of the floristic, historic aspects and the wildlife of the protecte \\
\hline Entrance fee & COST & Entrance fee $(2,5,7,10$ Euro $)$ \\
\hline
\end{tabular}


Table 3 - Excluded attributes in the experimental design for group and wave

\begin{tabular}{llll}
\hline \hline Outdoor group & Second wave & Third wave & Fourth wave \\
Hikers & $\begin{array}{l}\text { Climbing routes, via- } \\
\text { ferrata }\end{array}$ & $\begin{array}{l}\text { Trails, challenging } \\
\text { excursions }\end{array}$ & Trail signs, alpine huts \\
Picnickers & $\begin{array}{l}\text { Climbing routes, via- } \\
\text { ferrata }\end{array}$ & $\begin{array}{l}\text { Trails, challenging } \\
\text { excursions }\end{array}$ & Alpine huts, congestion \\
Mountain Bikers & $\begin{array}{l}\text { Climbing routes, via- } \\
\text { ferrata }\end{array}$ & Trails, trail signs & Thematic itineraries, alpine huts \\
Via-ferrata users & $\begin{array}{l}\text { Thematic itineraries, } \\
\text { climbing routes }\end{array}$ & Via-ferrata, trails & $\begin{array}{l}\text { Challenging excursions, } \\
\text { information }\end{array}$ \\
Climbers & $\begin{array}{l}\text { Thematic itineraries, } \\
\text { challenging excursions }\end{array}$ & Trails, climbing routes & Via-ferrata, alpine huts \\
\hline
\end{tabular}




\section{Table 4 - Example of choice task in choice experiment of the first wave}

\begin{tabular}{|c|c|c|c|}
\hline $\begin{array}{l}\text { Which of the following alternative } \\
\text { would you choose? }\end{array}$ & Alternative A & Alternative B & Neither \\
\hline Thematic itineraries (n.) & 5 in addition & 5 in addition & \\
\hline Trails (km) & 350 (baseline) & 300 (1/7 less) & \\
\hline Trail signs & vertical + horiz. $200 \mathrm{~m}$ & vertical only & \\
\hline Managed Trails Excursions (hours) & 6 & 1 & \\
\hline Climbing routes (n.) & 40 in addition & 20 in addition & \\
\hline Via-ferrata & Complete iron cable & Complete iron cable + artif. holds & \\
\hline Alpine huts (n.) & 23 (3 in addition) & 17 (3 less) & \\
\hline Congestion (n. of people) & between 20 e 50 & more than 50 & \\
\hline Information & leaflet & brochure & \\
\hline Entrance fee $(€)$ & 2 & 2 & \\
\hline Choice & & & \\
\hline
\end{tabular}


Table 5 - Summary of model results.

\begin{tabular}{|c|c|c|c|c|c|}
\hline \multirow[b]{2}{*}{ Attribute } & \multicolumn{2}{|c|}{ RUM } & & \multicolumn{2}{|c|}{ RRM } \\
\hline & Coeff & $|t-s t a t|$ & & Coeff & $|t-s t a t|$ \\
\hline $\mathrm{COST}$ & -0.1931 & 24.84 & & -0.1181 & 28.54 \\
\hline ITINERARIES & 0.0674 & 6.38 & & 0.0436 & 6.27 \\
\hline TRAILS & 0.0048 & 7.02 & & 0.0033 & 7.54 \\
\hline TRAIL SIGNS & 0.0007 & 3.57 & & 0.0005 & 3.70 \\
\hline MNGD_TRAILS_EXCURSIONS & 0.0181 & 1.66 & & 0.0120 & 1.70 \\
\hline CLIMBS & 0.0003 & 0.17 & & 0.0002 & 0.19 \\
\hline FERRATA_N1 & -0.1564 & 2.26 & & -0.0982 & 2.22 \\
\hline FERRATA_N2 & -0.1044 & 1.47 & & -0.0651 & 1.44 \\
\hline SHELTERS & 0.0242 & 2.44 & & 0.0162 & 2.53 \\
\hline CROWD & -0.0082 & 13.46 & & -0.0054 & 14.32 \\
\hline INFO1 & 0.0071 & 0.14 & & 0.0033 & 0.10 \\
\hline INFO2 & 0.0061 & 0.12 & & 0.0035 & 0.11 \\
\hline SQ & -1.4106 & 18.7 & & -0.7787 & 24.02 \\
\hline LL at zero & & & -6320.5 & & \\
\hline LL at conv. & -579 & .10 & & -580 & .04 \\
\hline \#Obs. & & & 5760 & & \\
\hline
\end{tabular}


Table 6 - Direct elasticities and relative differences

\begin{tabular}{|c|c|c|c|}
\hline & RUM & RRM & $\operatorname{abs}($ RUM $) / \operatorname{abs}(\mathbf{R R M})$ \\
\hline Attribute & Avg. Alt. A-B & Avg. Alt. A-B & Avg. Alt. A-B \\
\hline ITINERARIES & 0.1913 & 0.1970 & 0.943 \\
\hline TRAILS & 0.4886 & 0.5244 & 0.871 \\
\hline TRAIL SIGNS & 0.0676 & 0.0707 & 0.914 \\
\hline MNGD_TRAILS_EXCURSIONS & 0.0213 & 0.0221 & 0.914 \\
\hline FERRATA_N1 & -0.0180 & -0.0150 & 1.500 \\
\hline SHELTERS & 0.2263 & 0.2370 & 0.913 \\
\hline CROWD & -0.2045 & -0.2048 & 0.947 \\
\hline COST & -0.6267 & -0.6608 & 1.189 \\
\hline
\end{tabular}


Table 7 Predicted change in choice probabilities due to an increase of entrance fee by 15 percent

\begin{tabular}{|c|c|c|c|c|}
\hline & \multicolumn{2}{|l|}{ RUM } & \multicolumn{2}{|l|}{ RRM } \\
\hline & $\begin{array}{r}\text { Change in choice } \\
\text { probability }\end{array}$ & $\begin{array}{c}\text { Total } \\
\text { change }\end{array}$ & $\begin{array}{r}\text { Change in choice } \\
\text { probability }\end{array}$ & $\begin{array}{l}\text { Total } \\
\text { change }\end{array}$ \\
\hline $\begin{array}{l}\text { Alternative affected } \\
\text { (Average effect) }\end{array}$ & $-3.10 \%$ & $-100.00 \%$ & $-2.06 \%$ & $-100.00 \%$ \\
\hline $\begin{array}{l}\text { Other Alternative } \\
\text { (Average effect) }\end{array}$ & $1.52 \%$ & $48.81 \%$ & $0.98 \%$ & $47.53 \%$ \\
\hline $\begin{array}{l}\text { Status Quo } \\
\text { (Average effect) }\end{array}$ & $1.58 \%$ & $51.19 \%$ & $1.08 \%$ & $52.47 \%$ \\
\hline
\end{tabular}

